\title{
A Reliability-Based Optimization Model for Operational Management of CCHP System
}

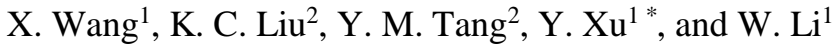 \\ ${ }^{1}$ MOE Key Laboratory of Regional Energy and Environmental Systems Optimization, North China Electric Power University, \\ Beijing 102206, China \\ ${ }^{2}$ State Key Laboratory of Power Grid Safety and Energy Conservation, Beijing 100085, China
}

Received 25 February 2021; revised 01 April 2021; accepted 23 May 2021; published online 30 June 2021

\begin{abstract}
The combined cooling, heating, and power (CCHP) system has been explored extensively due to its ability to reduce the carbon dioxide emission and improve the energy-utilization efficiency. However, the existing studies associated with CCHP system rarely concerned for the system reliability, although it was capable of enhancing the stability of operational patterns. In this study, predefined reliability coefficient (i.e., $r$ ) was incorporated innovatively into a CCHP system optimization model in order to examine the influence of reliability level on model results. A variety of solutions under different $r$ values were obtained, which effectively reflected the tradeoff between system economy and reliability. The CCHP system of a hotel in Shanghai, China, was used as a study case for demonstration. The generated results indicated that the system cost would increase with the increase of reliability level; meanwhile, the user requirements in cooling, heating and electricity were ensured greatly. The successful application of proposed optimization model in real case is expected to be a good example for CCHP system management.
\end{abstract}

Keywords: reliability evaluation, CCHP system, optimization model

\section{Introduction}

At present, the energy shortage has become main factor restricting the sustainable development of the country; meanwhile, the environmental pollution caused by traditional fossil energy combustion, greenhouse gas (GHG) emissions and extreme weather events are also problems that need to be solved urgently. It is critical to develop a distributed energy system, which used clean energy as raw material and realized the cascade utilization of energy in order to realize the goal of energy conservation and emission reduction. As an environment-friendly and high-efficiency energy system, combined cooling, heating and power (CCHP) system is capable of providing cooling, heating and electricity energy at the same time through utilizing the natural gas as main fuel. Firstly, the system uses natural gas as the main fuel, which releases heat through gas turbine, internal combustion engine or Sterling machine to drive power-generation equipment. Secondly, the waste heat flue gas with the high temperature generated by gas turbine or internal combustion engine will be provided to lithium bromide refrigeration unit and waste heat boiler to generate the cold energy and heat energy, respectively. When the quantity of cold, heat and electricity generated by the system is not enough to meet the users' needs, some auxiliary equipment such as exhaust heat boiler and elec-

${ }^{*}$ Corresponding author. Tel.: +86 1061772827; fax: 86-010-61772976.

E-mail address: xuye@ncepu.edu.cn (Y.Xu).

ISSN: 2663-6859 print/2663-6867 online

(c) 2021 ISEIS All rights reserved. doi:10.3808/jeil.202100060. tric chiller would be enabled; meanwhile, the insufficient electric quantity will be supplied through the power grid purchase.

Under rational structure composition and suitable operation strategy, the CCHP system exhibited the characteristics with the low cost and high-utilization efficiency. Therefore, it has been widely promoted and applied at the worldwide scale (Lin et al., 2007; Wei et al., 2007; Gu et al., 2010). For instance, Lin et al. (2007) analyzed the Sterling heat engine cycle and thermal efficiency and concluded that the combined cold, heat and electricity supply based on Sterling heat engine is a prospective choice for the energy system development in our country. Wei et al. (2007) studied the structure of CCHP system with micro gas turbine as the core and compared the economy between the combined and separate supply system through a practical case. It is proved that the combined supply system has great advantages. Gu et al. (2010) introduced the characteristics and system configuration of the co-generation system, and analyzed the research development of the triple generation system in the aspects of waste heat recovery and utilization, evaluation criteria of the triple generation system, optimization design and energy saving analysis. How to realize rational system structure design and generate optimal system operation pattern is a hotspot at present. Based on the operational research theory and the deep understanding of the system elements and structure, an optimization model aimed at the maximum revenue, minimum energy consumption and pollutants discharge was established and used in many countries and regions (Kong et al., 2005; Tan et al., 2014; Li et al., 2016). For example, Tan et al. (2014) proposed the multi-objective optimization model of CCHP system and appli- 
ed it for meeting the energy requirements in Guangdong higher Education Center. The best operation scheme under various system objectives is provided finally. Li et al. (2016) proposed a fuzzy optimization method, which calculates the weight values of different objectives in CCHP system more reasonably and converts the multi-objective optimization model into singleobjective one in order to find the optimal strategy. Kong et al. (2005) used a linear programming model to determine the output strategy of gas turbine, absorption refrigerator and auxiliary boiler in CCHP system in order to minimize the total energy cost of the system. The above results show that based on the predetermined model objectives such as improving the energy efficiency and maximizing the economic benefit according to the optimization algorithm, the CCHP system owns a good economy while meeting the load needs of users, which lays a good foundation for future research. However, the cooling and thermoelectric load was fluctuated in a large range subjected to the influence of external meteorological factors (including temperature, humidity and radiation) and users themselves (including scale change and production activity arrangement). If it is not concerned in the design and implementation of the system operation scheme, it will have a great impact on the reliability of the system operation and will lead to poor user experience. The reliability analysis and evaluation of the CCHP system can effectively identify the potential adverse factors, avoid systemfailure risk and promote the system performance. On the contrary, if the system reliability was not incorporated into the decision-making process, it means that the operation scheme is unreasonable and the user requirements may not be fully met, which leads to the reduction of system economy and user-satisfaction degree. Currently, the research related to the reliability of CCHP system is limited, and most of them are the qualitative analysis (Cui and Tang, 2017; He et al., 2019). For example, He et al. (2019) proposed a Monte Carlo method combined with important sampling method to evaluate the system reliability. Cui and Tang (2017) proposed an optimization model of the CCHP system with the objective function of minimum operating cost. Finally, the optimal operational patterns in different periods were identified and their respective reliability was evaluated.

Above studies were incapable of realizing the quantitative analysis to the system reliability level, which led to the difficulty in the decision maker's scheme design. Therefore, taking a five-star hotel in Shanghai as an example, this paper developed a CCHP optimization model based on reliability evaluation, which defines and quantifies reliability into a series of numerical values and effectively combines it into constraint conditions. Based on the predetermined reliability level, the facilities' output and economic costs of CCHP system under different reliability conditions are identified. Compared with the traditional optimization model, the proposed model can effectively provide more stable energy supply services for users with the costs as low as possible.

\section{Case Study}

\subsection{Background}

This study selected a hotel in Shanghai as the research object. The hotel is located in Pudong New area, covering an area of 53,330 $\mathrm{m}^{2}$, with 32 floors, a total height of 99.15 meters, a landscaping ratio of $50 \%$ and 400 ecological parking spaces. Shanghai, as the economic center of coastal areas and Yangtze River Basin in China, has high passenger throughput. Pudong New area is located in the east of Shanghai. It is the intersection of the middle point of China's coast and the mouth of the Yangtze River. It has convenient transportation, broad hinterland and superior geographical location. For the above reasons, the hotel has the characteristics of large passenger flow, high occupancy rate (average monthly occupancy rate as high as 60\%), a variety of energy-type requirements (including electrical, heating, cooling and domestic hot water), and high energy consumption (average cooling, heating and power consumption of 1,002.77, $1,542.83$ and $1,112.03 \mathrm{MJ} / \mathrm{m}^{3}$ ), as well as high reliability requirements for energy supply. Due to its subtropical monsoon climate, the four seasons in Shanghai are very distinct, where they are performed as warm in spring, hot in summer, cool in autumn and cold in winter, respectively. There is obvious cooling demand in the summer and heating demand in the winter. Conversely, the heating and cooling demand in other two seasons (i.e., spring and autumn) are relatively consistent. Therefore, the peak period of the hotel's cooling demand is mainly concentrated in the June to September of summer; the peak period of heating demand occurs in December to February of winter. Other months, including March, April, May, October and November, are uniformly defined as the transition season. Normally, the variation range of the hotel's annual power supply load demand is slight. However, when it comes to summer, the required power reaches the peak value owing to the long service time of air conditioners. Figure 1 shows the monthly average cooling and heating load of the hotel, which varies over the twelve seasons. Therefore, the acts that accurately estimate the energy demand of the hotel and continuously adjust the operation strategy of the CCHP system are capable of meeting the energy demand and reducing the system cost.

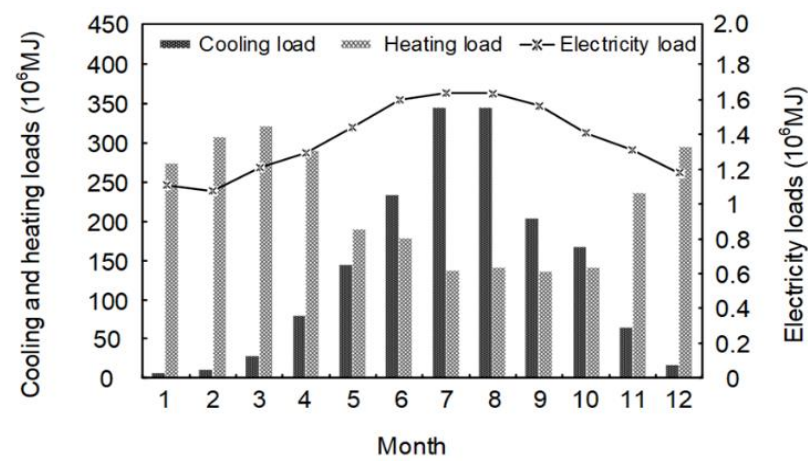

Figure 1. Schematic diagram of the hot, cold, and power load of a hotel in Shanghai.

The typical day in August of the summer is selected for analysis, since its average temperature is the highest and thus owns the largest cooling demand. The cold and hot load required for this typical day is shown in Figure 2. As shown in Figure 2, the cold demand of the hotel is highly volatile throughout the day, where the peak and valley periods occur at 14 
o'clock in the afternoon and 5 o'clock in the morning, being $964,363.5$ and 150,333.8 MJ, respectively. Compared with the cold load, the variations in electrical and thermal load are relatively stable. Among them, the highest and lowest electric demands were 2,930.2 $\mathrm{kWh}$ at $12 \mathrm{am}$ and $1,272.4 \mathrm{kWh}$ at $4 \mathrm{am}$, respectively. The highest and lowest heating demand were 404,323.8 $\mathrm{MJ}$ at $21 \mathrm{pm}$ and 17,166.8 $\mathrm{MJ}$ at $3 \mathrm{am}$, respectively. Similarly, the typical day in March of the winter is considered as the representative with the highest heating requirement. Figure 3 described its energy requirements, where the heating demands varies from $195,620.4 \mathrm{MJ}$ at $19 \mathrm{pm}$ to $663,453.35 \mathrm{MJ}$ at $3 \mathrm{am}$. The cooling energy is required only from 9 am to $22 \mathrm{pm}$ all day, and the maximum cold load is $86,569.7 \mathrm{MJ}$ at $12 \mathrm{am}$; the changes in the electric load is from $852.6 \mathrm{kWh}$ at 4 am to $2,351.4 \mathrm{kWh}$ at $17 \mathrm{pm}$. Correspondingly, the typical day in October of the transition season is chosen due to the smallest difference between cold and heat loads. The cold and heat energy required for this typical day is shown in Figure 4. As can be seen from it, the cold demand fluctuates between $14,535.9 \mathrm{MJ}$ at $0 \mathrm{am}$ and 508,756.2 MJ at $13 \mathrm{pm}$. The extreme values for the electric demand are $2497.7 \mathrm{kWh}$ at $17 \mathrm{pm}$ and $1029.0 \mathrm{kWh}$ at $3 \mathrm{am}$, respectively. The highest and lowest heat requirements are 290,028.9 MJ at $17 \mathrm{pm}$ and 62,346.2 $\mathrm{MJ}$ at $3 \mathrm{am}$, respectively.

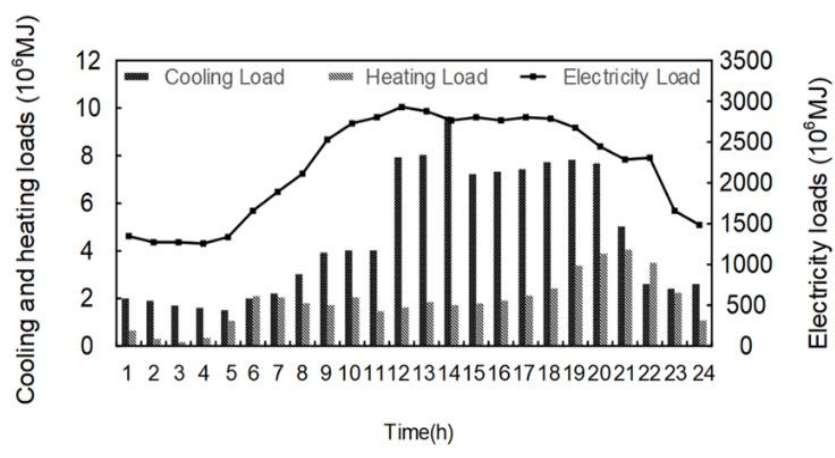

Figure 2. The cold, heat, and electricity load in a typical day of summer.

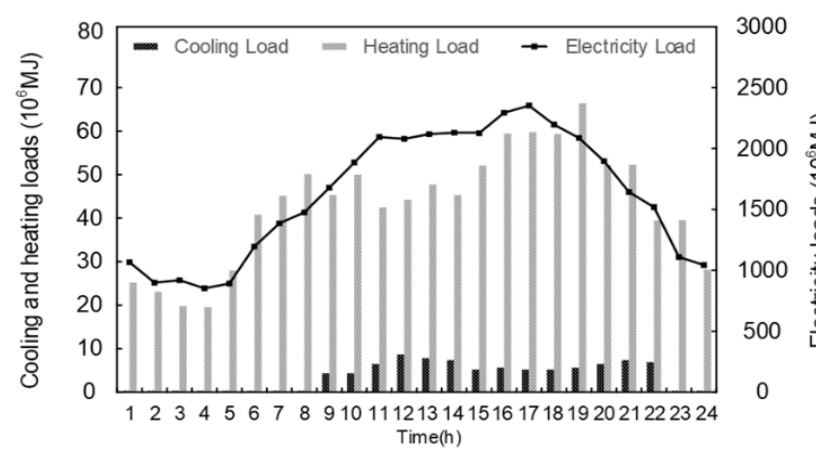

Figure 3. The cold, heat, and electricity load in a typical day of winter.

\subsection{System Description}

CCHP system is a typical distributed energy system which realizes the cascade utilization of energy and the integrated provision of cooling, heating and power. It is accompanied with the low cost, high energy-utilization efficiency and low pollutants emission. Figure 5 shows the structure and operation mechanism of CCHP system of targeted hotel. As shown in Figure 5, the hotel's CCHP system consists of five parts: gas turbine, waste heat boiler, gas-fired boiler, heat exchange and lithium bromide refrigerator, respectively. Firstly, the gas turbine burns natural gas in its combustion chamber and converts part of fuel's heat energy into the electric energy. At the same time, the waste heat flue gas with the high temperature generated in the conversion process is provided to the absorption chiller unit and the waste heat boiler through the heat recovery system for generating the cooling and heating energy, respectively. Under the context of utilizing the waste heat in priority, the gas-fired boiler is considered as the auxiliary cold and heat source when the cooling and heating capacity provided through above process are not enough to meet the users' needs, where the flue gas generated by the gas-fired boiler directly provides the heat energy or was utilized by the absorption chiller to generate cool energy. As for insufficient electricity load, it can be supplemented by the power purchase of public power grid.

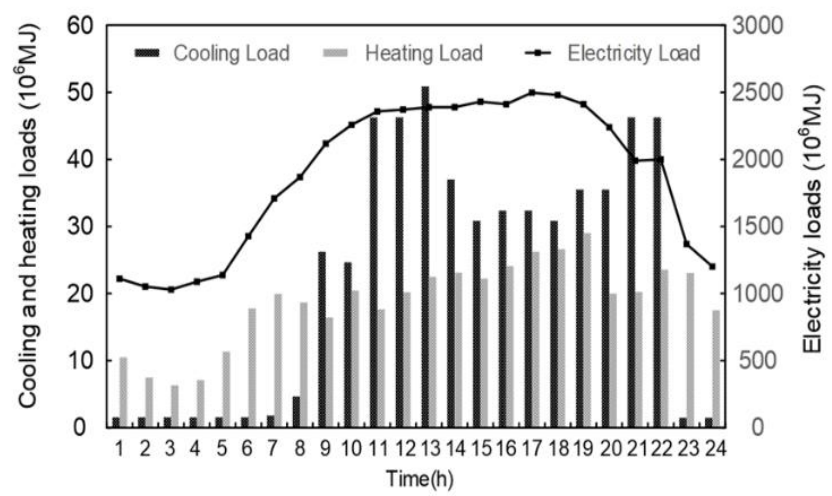

Figure 4. The cold, heat, and electricity load in a typical day of transition.

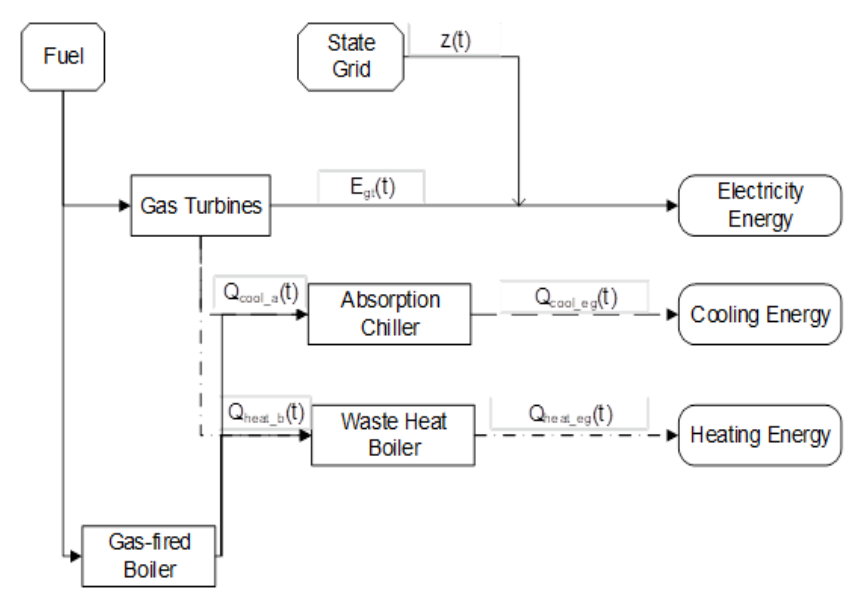

Figure 5. The structure and components of the CCHP system. 


\section{Methodology}

\subsection{The Formulation of CCHP System Operation Optimization Model}

As mentioned in the section "Introduction", the operation strategy of CCHP system has a vital impact on the system performance, so it is of great practical significance to optimize the operation strategy and achieve the system targets. In this paper, the minimization of total system cost is considered as the objecttive function, which included the operation cost, equipment maintenance cost and environmental cost. Major constraints are the balance between energy supply and demand and the limitations in the equipment capacity.

\subsubsection{Objective Functions}

$$
\begin{aligned}
& \text { Minimize } f=f_{1}+f_{2}+f_{3} \\
& f_{1}=\sum_{t=1}^{n} C_{n g}(t) \times\left[V_{n g}(t)+\alpha \times V_{n g_{-} a}(t)+\beta \times V_{n g_{-} b}(t)\right] \\
& +\sum_{t=1}^{n} \delta \times C_{e l e}(t) \times E_{s g}(t) \\
& f_{2}=C_{g t} \sum_{t=1}^{n} E_{g t}(t)+\mu C_{b} \sum_{t=1}^{n} Q_{b}(t)+\mu C_{a c} \sum_{t=1}^{n} C_{a}(t) \\
& f_{3}=\sum_{j=1}^{m} V_{j} \times Q_{j}
\end{aligned}
$$

where $f_{1}$ is annual operational cost; $f_{2}$ is annual maintenance $\operatorname{cost} ; f_{3}$ is annual environmental cost; $n$ is the number of hours throughout the year, being 8,$760 ; C_{n g}(t)$ is the price of natural gas during the $t$ period, $¥ / \mathrm{m}^{3} ; V_{n g}(t)$ is the amount of natural gas consumed by the gas turbine during the $\mathrm{t}$ period, $\mathrm{m}^{3} ; \alpha$ is 0 or 1 , where it equals to 1 when the recovery waste gas is allocated to the absorption refrigerator, otherwise $0 ; V_{n g_{-} a}(t)$ is the natural gas quantity consumed by the absorption refrigerator during the $t$ period, $\mathrm{m}^{3} ; \beta$ is 0 or 1 , the value " 1 " occurs at that the natural gas is utilized by the waste heat boiler, otherwise take $0 ; V_{n g \_b}(t)$ is the amount of natural gas supplemented to the gas-fired boiler during the period, $\mathrm{m}^{3} ; \delta$ is 0 or 1 , where it is 1 when the system buys electricity from the public power grid, otherwise 0 ; $C_{\text {ele }}(t)$ is the electricity selling price of the public power grid during the $t$ period, $¥ / \mathrm{kWh} ; E_{s g}(t)$ is the electricity requirement at the $t$ period, $\mathrm{kWh} ; C_{g t}$ is the maintenance cost of the gas turbine, $¥ / \mathrm{kW} ; E_{g t}(t)$ is the electricity-generation amount of the gas turbine at $t$ period, $\mathrm{kW} ; \mu$ is the conversion coefficient between $\mathrm{MJ}$ and $\mathrm{kWh}$, i.e. $1 \mathrm{MJ}=0.278 \mathrm{kWh} ; C_{b}$ is the maintenance cost of the boiler, $¥ / \mathrm{kW} ; Q_{b}(t)$ is the heat supply of the boiler at $t$ period, $\mathrm{kW} ; C_{a c}(t)$ is the maintenance cost of the absorption refrigerator, $¥ / \mathrm{kW} ; C_{a}(t)$ is the cooling capacity of absorption refrigerator at $t$ period, $\mathrm{kW} ; m$ is the type of the pollutants; $V_{j}$ is the charge cost caused by the discharge of $j$ pollutants, $¥ / \mathrm{kg}$; $Q_{j}$ is the discharge magnitude of $j$ pollutant, $\mathrm{kg}$. Objective function (1a) represents total cost of CCHP system, which includes annual operating $\operatorname{cost} f_{1}$, annual maintenance $\operatorname{cost} f_{2}$ of main equipments, and annual environmental cost $f_{3}$. Among them, $f_{l}$ included two parts: (i) operational cost of two facilities, i.e., $C_{n g}(t)$ $\times\left[V_{n g}(t)+\alpha \times V_{n g \_a}(t)+\beta \times V_{n g \_} b(t)\right]$ and (ii) the purchase cost of the electricity from the power grid, i.e., $\delta \times C_{\text {ele }}(t) \times E_{s g}(t) ; f_{2}$ mainly includes annual maintenance costs of gas turbine, boiler, and lithium bromide refrigerator (i.e., $C_{g t} \sum_{t=1}^{8760} E_{g t}(t), \mu C_{b} \sum_{t=1}^{8760} Q_{b}(t)$, and $\left.\mu C_{a c} \sum_{t=1}^{8760} C_{a}(t)\right) ; f_{3}$ is the total charge of emission discharge $\sum_{j=1}^{m} V_{j} \times Q_{j}$.

\subsubsection{Constraints}

(i) Constraints of equipment capacity:

$$
E_{g t}(t)=y(t) \times P_{g t} \times t
$$

$V_{n g}(t)=\frac{\lambda \times E_{g t}(t)}{\eta_{g t} \times H_{u}}$

$Q_{e g}(t)=\frac{\lambda \times E_{g t}(t) \times\left(1-\eta_{g t}-\eta_{\text {loss }}\right)}{\eta_{g t}}$

$Q_{\text {cool_eg }}(t)=Q_{e g}(t) \times x(t) \times \eta_{a_{-} h r} \times C O P_{a}$

$V_{n g_{-} a}(t)=\frac{Q_{\text {cool_a }}(t)}{C O P_{a} \times \eta_{a_{-} c} \times H_{u}}$

$Q_{\text {heat_eg }}(t)=Q_{e g}(t) \times(1-x(t)) \times \eta_{b_{-} h r}$

$V_{n g_{-} b}(t)=\frac{Q_{\text {heat } b}(t)}{\eta_{b_{-} c} \times H_{u}}$

where $E_{g t}(t)$ is the power generation provided by the gas turbine during the $t$ period, $\mathrm{kWh} ; P_{g t}$ is the rated power of gas turbine, $\mathrm{KW} ; y(t)$ is the operational state of gas turbine in $t$ period, where the gas turbine runs at full load with $y(t)=1$; conversely, $y(t)=0$ means that the gas turbine stops running; $V_{n g}(t)$ is the amount of natural gas consumed by the gas turbine during the $t$ period, $\mathrm{m}^{3} ; \lambda$ is the conversion coefficient between $\mathrm{kWh}$ and $\mathrm{MJ}$, i.e., $1 \mathrm{kWh}=3.6 \mathrm{MJ} ; \mathrm{Hu}$ is the calorific value of natural gas, $\mathrm{MJ} / \mathrm{m}^{3} ; \eta_{g t}$ is rated power generation efficiency of gas turbine; $Q_{e g}(t)$ is the stem amount extracted from the gas turbine during the $\mathrm{t}$ period, $\mathrm{MJ}$; $\eta_{\text {loss }}$ is the heat-loss efficiency of gas turbine; $Q_{\text {cool_eg }}(t)$ is the cooling amount produced by the absorption refrigerator through using the steam extracted from the gas turbine during the $t$ period, $\mathrm{MJ} ; \eta_{a_{-} h r}$ is the heat recovery efficiency of absorption refrigerator; $C O P_{a}$ is the refrigeration coefficient of absorption refrigerator; $x(t)$ is the allocation ratio of the recovery steam between absorption refrigerator and boiler, where the condition $x(t)=1$ occurs at all steam sourced from the gas turbine is allocated to the absorption refrigerator; $x(t)=$ 0 means that all steam enters into the boiler; $V_{n g \_}(t)$ is consum- 
ed natural gas volume of boiler when the cooling amount provided by CCHP system is not enough to meet the needs of the user, $\mathrm{m}^{3} ; Q_{\text {cool_a }}(t)$ is the capacity of absorption refrigerator in $t$ period, $\mathrm{MJ} ; \eta_{a_{-} c}$ is the combustion efficiency of the absorption refrigerator; $Q_{\text {heat_eg }}(t)$ is the heat amount produced by the boiler through using the steam extracted from gas turbine during the $t$ period, MJ; $\eta_{b_{-} h r}$ is the operation efficiency of boiler; $V_{n g \_} b(t)$ is consumed natural gas volume of boiler when the heating amount provided by CCHP system is not enough to meet the needs of the user, $\mathrm{m}^{3} ; Q_{\text {heat }} b(t)$ is the heat provision of boiler in $t$ period, $\mathrm{MJ} ; \eta_{b_{-}}$is the combustion efficiency of boiler. Constraint (1b) calculates the electricity-generation amount of gas turbine; constraint (1c) reflects the relationship between the electricity generation and natural gas consumption of gas turbine; constraint (1d) provides recovery heat flue gas amount with the high temperature released by gas turbine; constraint (1e) determines the cooling amount generated by the absorption refrigerator through using the steam extracted from the gas turbine; constraint (1f) estimates the consumed natural gas amount for the supplement of the cooling amount; constraint (1g) reflected the relationship between heat generation amount of boiler; constraint (1h) estimates the consumed natural gas amount and generated heat of supplemental combustion.

(ii) Constraints of energy balance:

$$
\begin{aligned}
& E_{g t}(t)+z(t)=E(t) \\
& z(t)<E(t) \\
& Q_{\text {cool_eg }_{-}}(t)+Q_{\text {cool_a }_{-}}(t)=Q_{\text {cool }}(t) \\
& Q_{\text {cool_a }_{-}}(t)<Q_{\text {cool }}(t) \\
& Q_{\text {heat_eg }}(t)+Q_{\text {heat_b }}(t)=Q_{\text {heat }}(t) \\
& Q_{\text {heat_b }}(t)<Q_{\text {heat }}(t)
\end{aligned}
$$

where $z(t)$ is purchased electricity amount sourced from the public grid, $\mathrm{kWh} E(t)$ is the electric requirement of users at $t$ period, kWh; $Q_{\text {cool }}(t)$ is required cooling amount at $t$ period, MJ; $Q_{\text {heat }}(t)$ is required heating amount at $t$ period, MJ. The constraints (1i), (1k) and (1m) regulate the balance of electric, cold and heat requirement and their respective supply, respectively. Constraint (1j), (11), and (1n) require that purchased electricity amount, supplementary cooling and heating amount should be lower than the required amount of users, respectively.

(iii) Constraints of facilities' capacity:

$$
\begin{aligned}
& E_{g t_{-} \min } \leq E_{g t}(t) \leq E_{g t_{-} \max } \\
& Q_{a c_{-} \min } \leq Q_{\text {cool_eg }}(t) \leq Q_{a c_{-} \max }
\end{aligned}
$$

$Q_{\text {rec_min }} \leq Q_{\text {heat }_{-} e g}(t) \leq Q_{\text {rec_max }}$

where $E_{g t \_m i n}$ and $E_{g t \text { max }}$ represent the minimum and maximum electricity output of gas turbine during $t$ period, respectively, $\mathrm{kWh} ; Q_{a c_{-} \min }$ and $Q_{a c_{-} \max }$ are the minimum and maximum cold output of absorption refrigerator during $t$ period, respectively, MJ; $Q_{\text {rec_min }}$ and $Q_{\text {rec_max }}$ are the minimum and maximum heat output of boiler during $t$ period, respectively, MJ; The constraints (1o) to (1q) regulate the range of the output of gas turbine, absorption refrigerator and boiler, respectively.

\subsection{The Incorporation of Reliability Theory into the Optimization Model}

The investigated results of targeted hotel (as shown in the section 2.1) demonstrated that the electric, cooling and heating requirements own the large variation trend, which leads to the difficulties in generating rational operational pattern of CCHP system and potential imbalance between energy supply and demand. Therefore, it is necessary to incorporate the reliability estimation of CCHP system into the optimization model developed in the section 3.1. In this study, the reliability coefficient $r_{i}$ is predefined to reflect the reliability level, where $i=1,2,3$ represents the type of the user demand. Equations (2) describe the reliability measures associated with the electric, cooling and heating provisions:

$$
\begin{aligned}
& P\left\{E_{\text {facility }}(t) \geq E(t)\right\} \geq r_{1} \\
& P\left\{Q_{c}(t) \geq Q_{\text {cool }}(t)\right\} \geq r_{2} \\
& P\left\{Q_{h}(t) \geq Q_{\text {heat }}(t)\right\} \geq r_{3}
\end{aligned}
$$

where $E_{\text {facility }}(t)$ is the total electricity amount provided by the system and the power grid, which equals to $E_{g t}(t)+z(t) ; Q_{c}(t)$ is the supplied cooling amount of the system, MJ; $Q_{h}(t)$ the supplied heating amount of the system, MJ. Referring to $\mathrm{Hu}$ and Cho (2014), it can be seen that three types of energy requirements at $t$ time are independent of each other and approximately follow the normal distribution as follows:

$$
\begin{aligned}
& E(t) \sim N\left(\mu_{1}, \sigma_{1}^{2}\right) \\
& Q_{\text {cool }}(t) \sim N\left(\mu_{2}, \sigma_{2}^{2}\right) \\
& Q_{\text {heat }}(t) \sim N\left(\mu_{3}, \sigma_{3}^{2}\right)
\end{aligned}
$$

Based on existing data information of the user's energy demand, the mean value $\mu$ and standard deviation $\delta$ involved in the normal distribution are estimated. According to the stochastic optimization theory, the in Equations (2a) to (2c) are transformed their respective equivalents, being ( $2 \mathrm{~g})$ to $(2 \mathrm{i})$, respectively: 
$E(t)=\mu_{1}(t)+\phi^{-1}\left(r_{1}\right) \times \sigma_{1}(t)$

$Q_{\text {cool }}(t)=\mu_{2}(t)+\phi^{-1}\left(r_{2}\right) \times \sigma_{2}(t)$

$Q_{\text {heat }}(t)=\mu_{3}(t)+\phi^{-1}\left(r_{3}\right) \times \sigma_{3}(t)$

where $\varphi^{-1}$ is the inverse function of standard normal distribution. The Equations ( $2 \mathrm{~g}$ ) to (2i) represent the electrical, heating and cooling amounts provided by system at different reliability levels, which is incorporated into the constraints (1i), (1k) and $(1 \mathrm{~m})$ in the traditional optimization model in order to reduce the failure risk of CCHP system. Finally, the operational schemes under various reliability levels were obtained, which effectively reflected the trade-off between system economy and reliability.

In this study, the reliability-based optimization model for the CCHP system is coded and solved through software LINGO 12.0. This is mainly due to the facts that it owns many advantages, such as user-friendly interface, easy-to-edit language and a series of common equations and functions. The hardware facilities are listed as follows: (1) Operation System: Microsoft Windows 10; (2) CPU: Intel ${ }^{\circledR}$ Core $^{\mathrm{TM}}$ i5-4210H @ 2.90GHz; (3) RAM: 4GB. And the calculation time for solving this optimization model is within the few minutes.

\subsection{Data Collection and Parameter Analysis}

The main components of the CCHP system are the gas turbines, lithium bromide refrigerator and boilers, respectively. Table 1 describes their performance parameters. The maintenance cost of the facilities is a major expenditure, which effectively enhances their safety and reliability. Many factors, including regional disparity, operators' experience and technical background and facilities' service time, would affect the repair and maintenance cost. In this study, based on the literature review (Gamou et al., 2002; Ruan et al., 2009; Yang et al., 2009; Zhou, 2014; Brown et al., 2015), designed unit maintenance cost of the main equipment is reflected in Table 1 . The document "Regulations on the Administration of the Collection and Use of Sewage Charges", which has been implemented since 2003 in China, established the legal status of "pollution charge". Currently, the estimation of pollutant-discharge fees is mainly based on the expert survey method, willingness to pay method and alternative method for pollutant cost. According to local pollutant discharge standards, the fees charged by different pollutant discharges are determined through the pollutant cost substitution method, which are also shown in Table 1.

\section{Result Analysis and Discussion}

\subsection{Result Analysis}

Tables 2 to 4 demonstrate the output of main system equipments in the typical day over three seasons generated by reliability-based CCHP system optimization model, respectively. Referring to previous studies (Wang and Singh, 2008; Cho et al., 2009; Mago and Chamra, 2009; Ren et al., 2010; Zhou et al., 2013), in this study, the reliability level is designed as 0.85 ,
0.90 and 0.95 , respectively. It can be seen that different reliability levels will lead to a variety of operational scheme.

Table 1. Parameters Associated with CCHP System

\begin{tabular}{|c|c|c|}
\hline Category & Parameter & Value \\
\hline \multirow{4}{*}{$\begin{array}{l}\text { Gas } \\
\text { turbine }\end{array}$} & Rated power $P_{g t \_n}$ & $270 \mathrm{MW}$ \\
\hline & Power generation efficiency $\eta_{g t}$ & $30 \%$ \\
\hline & Heat loss efficiency $\eta_{\text {loss }}$ & $8 \%$ \\
\hline & Maintenance costs & $0.03 ¥ / \mathrm{kWh}$ \\
\hline \multirow{4}{*}{$\begin{array}{l}\text { Absorption } \\
\text { chiller }\end{array}$} & Rated power $P_{E C \_n}$ & $800 \mathrm{MW}$ \\
\hline & $\begin{array}{l}\text { Coefficient of performance } \\
\mathrm{COP}_{a}\end{array}$ & 1.2 \\
\hline & $\begin{array}{l}\text { Generator combustion } \\
\text { efficiency } \eta_{a_{c} c}\end{array}$ & $85 \%$ \\
\hline & Maintenance costs & $0.0008 ¥ / \mathrm{kWh}$ \\
\hline \multirow{3}{*}{$\begin{array}{l}\text { Waste heat } \\
\text { boiler }\end{array}$} & Rated power $P_{R E C_{-} n}$ & $900 \mathrm{MW}$ \\
\hline & Combustion efficiency $\eta_{b_{-}} c$ & $85 \%$ \\
\hline & Maintenance costs & $0.00216 ¥ / \mathrm{kWh}$ \\
\hline \multirow{4}{*}{$\begin{array}{l}\text { Economic } \\
\text { parameters }\end{array}$} & Electricity price of peak period & $0.98 ¥ / \mathrm{kWh}$ \\
\hline & Electricity price of flat period & $0.61 ¥ / \mathrm{kWh}$ \\
\hline & $\begin{array}{l}\text { Electricity price of valley } \\
\text { period }\end{array}$ & $0.31 ¥ / \mathrm{kWh}$ \\
\hline & Natural gas prices & $2.74 ¥ / \mathrm{m}^{3}$ \\
\hline \multirow{8}{*}{$\begin{array}{l}\text { Parameters } \\
\text { related to } \\
\text { pollutants } \\
\text { discharge }\end{array}$} & $\begin{array}{l}\text { Discharge amount of pollutant } \\
\mathrm{SO}_{2}\end{array}$ & $11.6 \mathrm{~kg} / 10^{6} \mathrm{~m}^{3}$ \\
\hline & Charged cost of pollutant $\mathrm{SO}_{2}$ & $1.00 ¥ / \mathrm{kg}$ \\
\hline & $\begin{array}{l}\text { Discharge amount of pollutant } \\
\mathrm{NO}_{\mathrm{x}}\end{array}$ & $0.0062 \mathrm{~kg} / 10^{6} \mathrm{~m}^{3}$ \\
\hline & Charged cost of pollutant $\mathrm{NO}_{\mathrm{x}}$ & $2.00 ¥ / \mathrm{kg}$ \\
\hline & $\begin{array}{l}\text { Discharge amount of pollutant } \\
\mathrm{CO}_{2}\end{array}$ & $2.01 \mathrm{~kg} / 10^{6} \mathrm{~m}^{3}$ \\
\hline & Charged cost of pollutant $\mathrm{CO}_{2}$ & $0.01 ¥ / \mathrm{kg}$ \\
\hline & $\begin{array}{l}\text { Discharge amount of pollutant } \\
\text { CO }\end{array}$ & $0 \mathrm{~kg} / 10^{6} \mathrm{~m}^{3}$ \\
\hline & Charged cost of pollutant $\mathrm{CO}$ & $0.16 ¥ / \mathrm{kg}$ \\
\hline
\end{tabular}

\subsubsection{Electric Supply}

According to the definition and measure of the system reliability, as the increase in the reliability level, users' requirements in the electricity, cool and heat amount would increase. Correspondingly, the energy output of major equipment also increases. For example, as the reliability level increases from 85 to $95 \%$, average power outputs of gas turbines throughout the day of summer are 2,201, 2,395 and 2,573 kWh, respective1y. Similarly, those of gas turbines throughout the day of winter are 1,687, 2,057 and 2,312 $\mathrm{kWh}$, respectively. The electricitygeneration amounts of transitional season were 1,964, 2,263 and $2,447 \mathrm{kWh}$, respectively. In fact, not only the reliability level exerts the influence on the operational scheme, but also the variations in the user's requirements at various time points. For example, in the summer, the minimum user demand occurs at $4 \mathrm{pm}$, leading to the minimum output of gas turbine. As the reliability level increases from 85 to $95 \%$, the electricity output is $1,307,1,621$ and $2,073 \mathrm{kWh}$, respectively. Conversely, in the summer, the maximum user demand occurs at 12:00, leading to 
Table 2. Operational Pattern of CCHP System in a Typical Day of the Summer Season

\begin{tabular}{|c|c|c|c|c|c|c|c|c|c|c|c|c|c|c|c|c|c|c|}
\hline \multirow{3}{*}{ Time } & \multicolumn{18}{|c|}{ Operation Loads in a Typical Summer Day } \\
\hline & \multicolumn{6}{|c|}{$r=85 \%$} & \multicolumn{6}{|c|}{$r=90 \%$} & \multicolumn{6}{|c|}{$r=95 \%$} \\
\hline & $\mathrm{a}$ & $\mathrm{b}$ & $\mathrm{c}$ & $\mathrm{d}$ & e & $\mathrm{f}$ & $\mathrm{a}$ & $\mathrm{b}$ & $\mathrm{c}$ & $\mathrm{d}$ & $\mathrm{e}$ & $\mathrm{f}$ & $\mathrm{a}$ & $\mathrm{b}$ & $\mathrm{c}$ & d & $\mathrm{e}$ & $\mathrm{f}$ \\
\hline 1:00 & 1400 & 0 & 8688 & 199775 & 0 & 67186 & 1737 & 0 & 10776 & 247798 & 0 & 83336 & 2221 & 0 & 13784 & 316951 & 0 & 106592 \\
\hline $2: 00$ & 1323 & 0 & 8211 & 189829 & 0 & 30069 & 1641 & 0 & 10185 & 235461 & 0 & 37297 & 2099 & 0 & 13027 & 301171 & 0 & 47706 \\
\hline $3: 00$ & 1323 & 0 & 8211 & 168982 & 0 & 17853 & 1641 & 0 & 10185 & 209603 & 0 & 22145 & 2099 & 0 & 13027 & 268097 & 0 & 28325 \\
\hline 4:00 & 1307 & 0 & 8109 & 158662 & 0 & 34298 & 1621 & 0 & 10058 & 196801 & 0 & 42542 & 2073 & 0 & 12865 & 251723 & 0 & 54414 \\
\hline 5:00 & 1389 & 0 & 8620 & 147727 & 0 & 110410 & 1723 & 0 & 10692 & 183239 & 0 & 136951 & 2204 & 0 & 13676 & 234375 & 0 & 175169 \\
\hline $6: 00$ & 1724 & 0 & 10698 & 197765 & 0 & 218001 & 2139 & 0 & 13270 & 245304 & 0 & 270405 & 2700 & 35 & 16753 & 313981 & 0 & 345866 \\
\hline 7:00 & 1966 & 0 & 12197 & 217112 & 0 & 212832 & 2438 & 0 & 15129 & 269302 & 0 & 263994 & 2700 & 419 & 16753 & 347054 & 0 & 337667 \\
\hline 8:00 & 2196 & 0 & 13628 & 300224 & 0 & 186522 & 2700 & 24 & 16753 & 372544 & 0 & 231359 & 2700 & 785 & 16753 & 481186 & 0 & 295924 \\
\hline 9:00 & 2630 & 0 & 16320 & 391341 & 0 & 178535 & 2700 & 562 & 16753 & 488903 & 0 & 221452 & 2700 & 1473 & 16753 & 630016 & 0 & 283253 \\
\hline 10:00 & 2700 & 139 & 16753 & 401330 & 0 & 211893 & 2700 & 821 & 16753 & 501831 & 0 & 262829 & 2700 & 1804 & 16753 & 646553 & 0 & 336176 \\
\hline 11:00 & 2700 & 216 & 16753 & 401330 & 0 & 152694 & 2700 & 917 & 16753 & 501831 & 0 & 189400 & 2700 & 1926 & 16753 & 646553 & 0 & 242255 \\
\hline $12: 00$ & 2700 & 347 & 16753 & 807833 & 0 & 168669 & 2700 & 1080 & 16753 & 1006051 & 0 & 209214 & 2700 & 2135 & 16753 & 1291485 & 0 & 267599 \\
\hline 13:00 & 2700 & 293 & 16753 & 818256 & 0 & 191690 & 2700 & 1012 & 16753 & 1018980 & 0 & 237769 & 2700 & 2048 & 16753 & 1308021 & 0 & 304124 \\
\hline 14:00 & 2700 & 177 & 16753 & 986185 & 0 & 178535 & 2700 & 869 & 16753 & 1227276 & 0 & 221452 & 2700 & 1865 & 16753 & 1574446 & 0 & 283253 \\
\hline 15:00 & 2700 & 216 & 16753 & 734871 & 0 & 185582 & 2700 & 917 & 16753 & 915550 & 0 & 230194 & 2700 & 1926 & 16753 & 1175728 & 0 & 294434 \\
\hline $16: 00$ & 2700 & 177 & 16753 & 745294 & 0 & 198738 & 2700 & 869 & 16753 & 928479 & 0 & 246511 & 2700 & 1865 & 16753 & 1192264 & 0 & 315305 \\
\hline $17: 00$ & 2700 & 216 & 16753 & 755717 & 0 & 219880 & 2700 & 917 & 16753 & 941407 & 0 & 272736 & 2700 & 1926 & 16753 & 1208801 & 0 & 348848 \\
\hline 18:00 & 2700 & 199 & 16753 & 786987 & 0 & 251828 & 2700 & 896 & 16753 & 980194 & 0 & 312364 & 2700 & 1900 & 16753 & 1258411 & 0 & 399535 \\
\hline 19:00 & 2700 & 84 & 16753 & 797410 & 0 & 351432 & 2700 & 753 & 16753 & 993122 & 0 & 435911 & 2700 & 1717 & 16753 & 1274948 & 0 & 557560 \\
\hline 20:00 & 2542 & 0 & 15775 & 782175 & 0 & 402643 & 2700 & 453 & 16753 & 973011 & 0 & 499432 & 2700 & 1333 & 16753 & 1249224 & 0 & 638809 \\
\hline 21:00 & 2378 & 0 & 14753 & 507563 & 0 & 420497 & 2700 & 249 & 16753 & 631118 & 0 & 521578 & 2700 & 1072 & 16753 & 811920 & 0 & 667134 \\
\hline 22:00 & 2400 & 0 & 14889 & 256113 & 0 & 363647 & 2700 & 276 & 16753 & 319393 & 0 & 451063 & 2700 & 1107 & 16753 & 413201 & 0 & 576941 \\
\hline 23:00 & 1724 & 0 & 10698 & 239457 & 0 & 233035 & 1737 & 0 & 13270 & 297019 & 0 & 289053 & 2700 & 35 & 16753 & 380128 & 0 & 369719 \\
\hline 24:00 & 1543 & 0 & 9574 & 261428 & 0 & 111819 & 1641 & 0 & 11875 & 324271 & 0 & 138699 & 2448 & 0 & 15189 & 414765 & 0 & 177406 \\
\hline
\end{tabular}

Note: The terms $a, b, c, d, e$ and $f$ represent the model results, being the outputs of gas turbine, purchased electricity amounts, the outputs of absorption chiller, supplementary cooling amount, the outputs of gas-fired boiler and supplementary heating amount, respectively. 
Table 3. Operational Pattern of CCHP System in a Typical Day of the Winter Season

\begin{tabular}{|c|c|c|c|c|c|c|c|c|c|c|c|c|c|c|c|c|c|c|}
\hline \multirow{3}{*}{ Time } & \multicolumn{18}{|c|}{ Operation Loads in a Typical Winter Day } \\
\hline & \multicolumn{6}{|c|}{$r=85 \%$} & \multicolumn{6}{|c|}{$r=90 \%$} & \multicolumn{6}{|c|}{$r=95 \%$} \\
\hline & $\mathrm{a}$ & $\mathrm{b}$ & $\mathrm{c}$ & $\mathrm{d}$ & $\mathrm{e}$ & $\mathrm{f}$ & $\mathrm{a}$ & $\mathrm{b}$ & $\mathrm{c}$ & $\mathrm{d}$ & $\mathrm{e}$ & $\mathrm{f}$ & $\mathrm{a}$ & $\mathrm{b}$ & $\mathrm{c}$ & $\mathrm{d}$ & $\mathrm{e}$ & $\mathrm{f}$ \\
\hline 1:00 & 1109 & 0 & 911 & 0 & 5557 & 256015 & 1376 & 0 & 1130 & 0 & 6893 & 317558 & 1760 & 0 & 1446 & 0 & 8816 & 406178 \\
\hline 2:00 & 935 & 0 & 911 & 0 & 4552 & 235492 & 1160 & 0 & 1130 & 0 & 5646 & 292101 & 1484 & 0 & 1446 & 0 & 7222 & 373617 \\
\hline 3:00 & 956 & 0 & 911 & 0 & 4669 & 200929 & 1185 & 0 & 1130 & 0 & 5791 & 249230 & 1516 & 0 & 1446 & 0 & 7407 & 318782 \\
\hline 4:00 & 887 & 0 & 911 & 0 & 4271 & 199174 & 1100 & 0 & 1130 & 0 & 5298 & 247052 & 1407 & 0 & 1446 & 0 & 6777 & 315997 \\
\hline 5:00 & 927 & 0 & 911 & 0 & 4505 & 286131 & 1150 & 0 & 1130 & 0 & 5588 & 354912 & 1471 & 0 & 1446 & 0 & 7148 & 453958 \\
\hline $6: 00$ & 1243 & 0 & 911 & 0 & 6328 & 417785 & 1542 & 0 & 1130 & 0 & 7850 & 518214 & 1972 & 0 & 1446 & 0 & 10040 & 662832 \\
\hline 7:00 & 1441 & 0 & 911 & 0 & 7474 & 461850 & 1788 & 0 & 1130 & 0 & 9270 & 572871 & 2287 & 0 & 1446 & 0 & 11858 & 732742 \\
\hline 8:00 & 1535 & 0 & 911 & 0 & 8011 & 512981 & 1903 & 0 & 1130 & 0 & 9937 & 636293 & 2435 & 0 & 1446 & 0 & 12710 & 813863 \\
\hline 9:00 & 1745 & 0 & 10828 & 34279 & 0 & 471476 & 2165 & 0 & 13431 & 42520 & 0 & 584812 & 2700 & 69 & 16753 & 54811 & 0 & 748015 \\
\hline $10: 00$ & 1960 & 0 & 12159 & 32948 & 0 & 519916 & 2431 & 0 & 15082 & 40868 & 0 & 644895 & 2700 & 409 & 16753 & 54811 & 0 & 824866 \\
\hline $11: 00$ & 2178 & 0 & 13516 & 54191 & 0 & 441336 & 2700 & 2 & 16753 & 67229 & 0 & 547427 & 2700 & 756 & 16753 & 90666 & 0 & 700197 \\
\hline $12: 00$ & 2162 & 0 & 13416 & 76617 & 0 & 459636 & 2682 & 0 & 16640 & 95035 & 0 & 570125 & 2700 & 730 & 16753 & 126087 & 0 & 729229 \\
\hline $13: 00$ & 2203 & 0 & 13667 & 67527 & 0 & 496234 & 2700 & 32 & 16753 & 83958 & 0 & 615521 & 2700 & 794 & 16753 & 112063 & 0 & 787295 \\
\hline $14: 00$ & 2215 & 0 & 13742 & 62986 & 0 & 471476 & 2700 & 47 & 16753 & 78419 & 0 & 584812 & 2700 & 814 & 16753 & 104979 & 0 & 748015 \\
\hline $15: 00$ & 2211 & 0 & 13717 & 40412 & 0 & 541444 & 2700 & 42 & 16753 & 50387 & 0 & 671599 & 2700 & 807 & 16753 & 69124 & 0 & 859022 \\
\hline $16: 00$ & 2385 & 0 & 14797 & 43888 & 0 & 617871 & 2700 & 258 & 16753 & 56039 & 0 & 766397 & 2700 & 1083 & 16753 & 76353 & 0 & 980276 \\
\hline $17: 00$ & 2445 & 0 & 15174 & 38955 & 0 & 621100 & 2700 & 333 & 16753 & 50387 & 0 & 770403 & 2700 & 1180 & 16753 & 69124 & 0 & 985399 \\
\hline 18:00 & 2284 & 0 & 14169 & 39960 & 0 & 616794 & 2700 & 132 & 16753 & 50387 & 0 & 765062 & 2700 & 923 & 16753 & 69124 & 0 & 978568 \\
\hline 19:00 & 2170 & 0 & 13466 & 45219 & 0 & 689991 & 2692 & 0 & 16703 & 56089 & 0 & 855855 & 2700 & 743 & 16753 & 76353 & 0 & 1094698 \\
\hline $20: 00$ & 1972 & 0 & 12235 & 55472 & 0 & 543597 & 2446 & 0 & 15176 & 68806 & 0 & 674269 & 2700 & 428 & 16753 & 90666 & 0 & 862438 \\
\hline 21:00 & 1709 & 0 & 10602 & 66126 & 0 & 543597 & 2119 & 0 & 13150 & 82022 & 0 & 674269 & 2700 & 11 & 16753 & 104979 & 0 & 862438 \\
\hline $22: 00$ & 1579 & 0 & 9798 & 62283 & 0 & 410120 & 1959 & 0 & 12153 & 77255 & 0 & 508706 & 2505 & 0 & 15545 & 98814 & 0 & 650671 \\
\hline 23:00 & 1154 & 0 & 911 & 0 & 5814 & 405382 & 1431 & 0 & 1130 & 0 & 7212 & 502830 & 1831 & 0 & 1446 & 0 & 9224 & 643154 \\
\hline 24:00 & 1085 & 0 & 911 & 0 & 5417 & 287372 & 1346 & 0 & 1130 & 0 & 6719 & 356452 & 1722 & 0 & 1446 & 0 & 8594 & 455927 \\
\hline
\end{tabular}

Note: The terms a, b, c, d, e and f represent the model results, being the outputs of gas turbine, purchased electricity amounts, the outputs of absorption chiller, supplementary cooling amount, the outputs of gas-fired boiler and supplementary heating amount, respectively. 
Table 4. Operational Pattern of CCHP System in a Typical Day of the Transition Season

\begin{tabular}{|c|c|c|c|c|c|c|c|c|c|c|c|c|c|c|c|c|c|c|}
\hline \multirow{3}{*}{ Time } & \multicolumn{18}{|c|}{ Operation Loads in a Typical Transition Day } \\
\hline & \multicolumn{6}{|c|}{$r=85 \%$} & \multicolumn{6}{|c|}{$r=90 \%$} & \multicolumn{6}{|c|}{$r=95 \%$} \\
\hline & $\mathrm{a}$ & $\mathrm{b}$ & $\mathrm{c}$ & $\mathrm{d}$ & $\mathrm{e}$ & $\mathrm{f}$ & $\mathrm{a}$ & $\mathrm{b}$ & $\mathrm{c}$ & $\mathrm{d}$ & $\mathrm{e}$ & $\mathrm{f}$ & $\mathrm{a}$ & $\mathrm{b}$ & $\mathrm{c}$ & $\mathrm{d}$ & $\mathrm{e}$ & $\mathrm{f}$ \\
\hline 1:00 & 1155 & 0 & 7167 & 9070 & 0 & 109000 & 1432.7 & 0 & 8889 & 11250 & 0 & 135202 & 1832 & 0 & 11370 & 14390 & 0 & 172933 \\
\hline 2:00 & 1094 & 0 & 6787 & 9451 & 0 & 77992 & 1356.6 & 0 & 8417 & 11722 & 0 & 96739 & 1735 & 0 & 10767 & 14994 & 0 & 123737 \\
\hline 3:00 & 1070 & 0 & 6640 & 9597 & 0 & 65776 & 1327.4 & 0 & 8236 & 11903 & 0 & 81587 & 1698 & 0 & 10535 & 15226 & 0 & 104356 \\
\hline 4:00 & 1131 & 0 & 7021 & 9217 & 0 & 73763 & 1403.4 & 0 & 8708 & 11432 & 0 & 91494 & 1795 & 0 & 11138 & 14622 & 0 & 117028 \\
\hline $5: 00$ & 1183 & 0 & 7342 & 8895 & 0 & 117927 & 1467.7 & 0 & 9107 & 11032 & 0 & 146274 & 1877 & 0 & 11649 & 14112 & 0 & 187096 \\
\hline 6:00 & 1485 & 0 & 9215 & 7023 & 0 & 184643 & 1842.0 & 0 & 11429 & 8710 & 0 & 229027 & 2356 & 0 & 14619 & 11142 & 0 & 292943 \\
\hline 7:00 & 1777 & 0 & 11028 & 8008 & 0 & 207194 & 2204.5 & 0 & 13679 & 9933 & 0 & 257000 & 2700 & 120 & 16753 & 13449 & 0 & 328722 \\
\hline 8:00 & 1942 & 0 & 12052 & 36099 & 0 & 194039 & 2409.2 & 0 & 14949 & 44777 & 0 & 240683 & 2700 & 382 & 16753 & 59641 & 0 & 307851 \\
\hline 9:00 & 2202 & 0 & 13661 & 259011 & 0 & 171018 & 2700 & 30.845 & 16753 & 321464 & 0 & 212127 & 2700 & 793 & 16753 & 415851 & 0 & 271326 \\
\hline 10:00 & 2348 & 0 & 14568 & 241867 & 0 & 212832 & 2700 & 212.12 & 16753 & 301324 & 0 & 263994 & 2700 & 1025 & 16753 & 390090 & 0 & 337667 \\
\hline 11:00 & 2451 & 0 & 15211 & 465744 & 0 & 183233 & 2700 & 340.76 & 16753 & 579815 & 0 & 227279 & 2700 & 1189 & 16753 & 746300 & 0 & 290707 \\
\hline $12: 00$ & 2466 & 0 & 15299 & 465656 & 0 & 210013 & 2700 & 358.31 & 16753 & 579815 & 0 & 260497 & 2700 & 1212 & 16753 & 746300 & 0 & 333194 \\
\hline 13:00 & 2484 & 0 & 15416 & 513690 & 0 & 233975 & 2700 & 381.70 & 16753 & 639542 & 0 & 290218 & 2700 & 1242 & 16753 & 822694 & 0 & 371210 \\
\hline $14: 00$ & 2484 & 0 & 15416 & 369236 & 0 & 240083 & 2700 & 381.70 & 16753 & 460363 & 0 & 297794 & 2700 & 1242 & 16753 & 593512 & 0 & 380900 \\
\hline $15: 00$ & 2527 & 0 & 15679 & 305144 & 0 & 231156 & 2700 & 434.33 & 16753 & 381190 & 0 & 286722 & 2700 & 1309 & 16753 & 492245 & 0 & 366737 \\
\hline $16: 00$ & 2508 & 0 & 15562 & 320938 & 0 & 250419 & 2700 & 410.94 & 16753 & 400636 & 0 & 310615 & 2700 & 1279 & 16753 & 517118 & 0 & 397299 \\
\hline $17: 00$ & 2598 & 0 & 16118 & 320382 & 0 & 272501 & 2700 & 522.04 & 16753 & 400636 & 0 & 338005 & 2700 & 1421 & 16753 & 517118 & 0 & 432333 \\
\hline 18:00 & 2579 & 0 & 16001 & 304822 & 0 & 276729 & 2700 & 498.65 & 16753 & 381190 & 0 & 343250 & 2700 & 1391 & 16753 & 492245 & 0 & 439041 \\
\hline 19:00 & 2508 & 0 & 15562 & 353412 & 0 & 301630 & 2700 & 410.94 & 16753 & 440917 & 0 & 374137 & 2700 & 1279 & 16753 & 568639 & 0 & 478548 \\
\hline 20:00 & 2329 & 0 & 14451 & 354524 & 0 & 207664 & 2700 & 188.73 & 16753 & 440917 & 0 & 257583 & 2700 & 995 & 16753 & 568639 & 0 & 329467 \\
\hline 21:00 & 2070 & 0 & 12842 & 468113 & 0 & 210483 & 2567.1 & 0 & 15928 & 580640 & 0 & 261080 & 2700 & 584 & 16753 & 746300 & 0 & 333940 \\
\hline 22:00 & 2079 & 0 & 12900 & 468055 & 0 & 244781 & 2578.8 & 0 & 16001 & 580567 & 0 & 303622 & 2700 & 598 & 16753 & 746300 & 0 & 388354 \\
\hline 23:00 & 1424 & 0 & 8834 & 6283 & 0 & 239613 & 1765.9 & 0 & 10957 & 7793 & 0 & 297211 & 1832 & 0 & 14016 & 9968 & 0 & 380155 \\
\hline 24:00 & 1249 & 0 & 7752 & 7365 & 0 & 181824 & 1549.6 & 0 & 9615.3 & 9135 & 0 & 225531 & 1735 & 0 & 12299 & 11686 & 0 & 288470 \\
\hline
\end{tabular}

the outputs of gas-fired boiler and supplementary heating amount, respectively. 
the maximum output of gas turbine, being 2,700 $\mathrm{kWh}$ under three reliability levels, respectively. Moreover, purchased electricity amounts are $347,1,080$ and $2,135 \mathrm{kWh}$ due to the supplied amounts of the gas turbine are incapable of meeting user's requirement. It can be seen that the operational mode of CCHP system ensures the full utilization of gas turbine in priority; the electricity purchase is considered as the supplementary way. This is because the natural gas was utilized by the gas turbine for the electricity supply; meanwhile, the recovery waste gas, as the byproduct, is absorbed by the absorption refrigerator or boiler to generate the cooling or heating amounts. This energycascade utilization way is beneficial to realize the minimization of total system cost compared to the way purchasing the electricity from the public grid. Similar situation also appears at other two seasons. For example, in the winter, the minimum electric demand occurs at $4 \mathrm{pm}$, as the reliability level increases from 85 to $95 \%$, the electricity output is $887,1,010$ and $1,407 \mathrm{kWh}$, respectively. The electricity requirement during this period is satisfied by the gas turbine and there is no need to purchase electricity from the grid. Conversely, under the maximum demand at $17 \mathrm{pm}$, the user's demand is satisfied by both gas turbine and public grid. As the reliability level increases from 85 to $95 \%$, the output of gas turbines is $2,445,2,700$ and $2,700 \mathrm{kWh}$, respectively; the purchasing electricity is 0,333 and $1,180 \mathrm{kWh}$, respectively.

\subsubsection{Cold Supply}

In the typical day of the summer, the high cold demand is satisfied by both absorption chiller and supplemental combustion facility, because the limited capacity of the gas turbine is incapable of supplying enough the waste gas to the absorption refrigerator for generating sufficient cooling amount. For example, the maximum user demand occurs at $14 \mathrm{pm}$, and along with the reliability level increased from 85 to $95 \%$, the absorption chillers reach their maximum level, being 16,753 MJ. The gap can be filled by the boiler, where its cooling provisions were $986,185,1,227,276$ and 1,574,446 MJ, respectively. The absorption refrigerator is preferred for its characteristic of the low cost, where it utilizes the recovery waste gas as the raw material. Compared with those in the summer, the cold demands in the winter would remarkably decrease, leading to various energy provision patterns. For instance, the minimum demand at 23:00 $\sim$ 8:00 is satisfied by the absorption refrigerator solely. Conversely, during the period from 9:00 to 22:00, user's cold demand exceeds the maximum capacity of the absorption refrigerator, the insufficient cooling amount was provided by the boiler's combustion. As the reliability level increased from 85 to $95 \%$, the peak value of supplementary cooling amount appeared at 12:00, being 76,617, 95,035 and 126,087 MJ, respectively. In the transition season, the large cooling demand is satisfied by both two equipments. The peak demand at 11:00 22:00 needs more outputs of the boiler. At the three levels of $0.85,0.9$ and 0.95 , the peak value of the supplementary amount appeared at $13 \mathrm{pm}$, being 529,106, 656,295 and 839,447 MJ, respectively.

\subsubsection{Heat Supply}

The limited capacity of gas turbine leads to the fact that the recovery waste gas utilized by absorption chiller and boiler is not enough to meet both cooling and heating demand. The determination of allocation proportion between two equipments is mainly dependent on the provision cost of cold and heat energy, where more waste gas is allocated to the absorption refrigerator in priority for generating the cooling amount. Correspondingly, the heat demand is mainly satisfied by the gas-fired boiler, rather than the waste heat boiler. For example, the high cooling demand in typical day of the summer leads to the fact that the gas-fired boiler is used to generate the heating energy. As the reliability level increased from 85 to $95 \%$, the maximum heat supply of the boiler appeared at $21 \mathrm{pm}$, being 420,497, 521,578 and $667,134 \mathrm{MJ}$, respectively. Similarly, in the transition season, at the three levels of $0.85,0.90$ and 0.95 , the peak value appeared at $19 \mathrm{pm}$, being $301,630,374,137$ and 478,548 MJ, respectively. On the contrary, the winter has the lowest cooling demand that the heat supply was satisfied by both two boilers. For example, as the reliability level increased from 85 to $95 \%$, the maximum heat supply of the gas-fired boiler appeared at 8:00, being 8,001, 9,937 and 12,710 MJ, respecttively. Moreover, heating supply amounts from waste heat boiler are 512,981, 636,293, 813,863 MJ, respectively.

\subsubsection{System Cost}

In fact, the introduction of the reliability level not only affects the decision variables, but also the objective value, where the increase in the reliability level means that the high energy demand would occur, resulting in the high system cost. In addition, the difference in the energy demand over three seasons also leads to the large variation in the system cost corresponding to the typical day in three seasons. It is clear that the system costs of the summer and winter are high than those of the transition season. For example, as the reliability level increased from 85 to $95 \%$, total system cost of typical day in the summer was $20.63,25.67$ and $32.93 \times 10^{6} \mathrm{RMB}$, respectively. The total system cost in the winter was $13.12,16.28$ and $20.89 \times 10^{6} \mathrm{RMB}$, respectively. As for the transition season, the system cost was $12.57,15.63$ and $20.08 \times 10^{6} \mathrm{RMB}$, respectively. With the increase in the reliability level, the variation in the system cost reflected the trade-off between system economy and reliability. The high reliability means user's energy demand was completely satisfied, although the high system cost was expected. Conversely, the low reliability was accompanied with the low system cost; however, the imbalance between the energy supply and demand may occur.

\subsection{Discussion}

In order to better reflect the advantage of the reliability estimation, the traditional optimization model of this CCHP system was formulated for comparison purpose. A variety of energy provision patterns under predetermined reliability levels at the typical day over three seasons were provided to the dispatcher, which ensured the balance between energy supply and demand; meanwhile, more decision spaces are beneficial to the generation of suitable schedule pattern according to the practical situation. On the contrary, the single solution is provided 
by the traditional model, where the operational cost in the summer, winter and transition season was $19.84,12.62$ and $12.09 \times$ $10^{6} \mathrm{RMB}$, respectively. Moreover, under the context of instable energy requirement, the low system cost may lead to the fact that the user's requirements were not satisfied and affect their experience (Xu et al., 2018; Wang et al., 2020).

However, proposed optimization model still needs to be improved, especially in following three aspects. Firstly, a more reasonable definition and estimation of reliability was necessary, which is capable of enhancing the stability of system operation and the satisfactory degree of the customers. Secondly, many interactive relationships involved in the CCHP system, including the consumed gas amount was how to correspond to the electricity generation and recovered waste gas quantity, were oversimplified subjected to limited data information and acquaintance in entire CCHP system. How to comprehensively and accurately describe the complex relationships associated with the CCHP system and incorporated them into the optimization model is very important. Thirdly, the on-off operation of gas turbine is an important step during the entire process of CCHP system. The energy consumption amounts and operational efficiency during this period are different from those in stationary phase, where they normally are calculated by aid of the piecewise function. Some successfully applications incorporating the on-off operation into the operation optimization models of the CCHP system have been reported recently, which provided well demonstration (Yong et al., 2008; Park et al., 2014; Cao and Dai, 2016). Therefore, the proposed optimization model could also reflect the influences of on-off operation on system economy and operational strategy in the future but additional computational efforts are required.

Finally, many system parameters are affected by socioeconomic, engineering, meteorological and environmental factors, and thus exhibit the uncertain characteristics. In the future, some uncertain optimization techniques, including random, fuzzy and interval optimization methods, should be incorporated into model to handle more-complex problems.

\section{Conclusion}

In this study, a reliability-based operation optimization model was developed for supporting the operational management of CCHP system, which had the advantages in following two aspects. In terms of methodology, the reliability measure was innovatively incorporated into traditional optimization model and effectively ensured the balance between energy supply and demand under the context of large fluctuation in users' energy requirement. In terms of practical application, a five-star hotel in Shanghai is taken as an example, which realized the first application of reliability-based optimization model in the CCHP system. A variety of the operational schemes of CCHP system under three reliability levels were provided to the dispatcher, which were capable of offering more stable energy-supply services and evaluating the trade-off between system economy and reliability. As shown in the obtained solutions, it could conclude that with the increase in the reliability level, user's demands in the electricity, cool and heat amounts would also increase, leading to the increase in the system cost. Total system cost was $46.33,57.58$ and $73.90 \times 10^{6} \mathrm{RMB}$ under three levels from 0.85 to 0.95 , respectively. Compared with the objective values and decision variables of reliability-based optimization model, total cost and the output of system facilities sourced from traditional optimization model were reduced. For example, annual total cost of the tradition optimization model is $44.54 \times 10^{6} \mathrm{RMB}$. In order to further enhance the accuracy and practicality of proposed model, it is necessary to determine more reasonable definition of reliability and truly reflect the operational situation of CCHP system as possible, such as the introduction of accurate input-output relations, on-off operation and the ramp constraint. Moreover, some uncertain optimization methods should be incorporated into the proposed optimization model for tackling more complex issues.

Acknowledgments. This research was supported by the National Key Research and Development Plan (2016YFA0601502), and the Open Fund of State Key Laboratory of Power Grid Safety and Energy Conservation (China Electric Power Research Institute) [No. 2020110045004620].

\section{References}

Brown, C., Gorgolewski, M. and Goodwill, A. (2015). Using physical, behavioral, and demographic variables to explain suite-level energy use in multiresidential buildings. Building and Environment, 89, 308-317. https://doi.org/10.1016/j.buildenv.2015.02.039

Cao, Y. and Dai, Y.P. (2016). Comparative analysis on off-design performance of a gas turbine and ORC combined cycle under different operation approaches. Energy Conversion and Management, 135, 86-100. https://doi.org/10.1016/j.enconman.2016.12.072

Cho, H., Mago, P.J., Luck, R. and Chamra, L.M. (2008). Evaluation of CCHP systems performance based on operational cost, primary energy consumption, and carbon dioxide emission by utilizing an optimal operation scheme. Applied Energy, 86(12), 2540-2549. https:// doi.org/10.1016/j.apenergy.2009.04.012

Cho, H., Mago, P.J., Luck, R. and Chamra, L.M. (2009). Evaluation of CCHP systems performance based on operational cost, primary energy consumption, and carbon dioxide emission by utilizing an optimal operation scheme. Applied Energy, 86(12), 2540-2549. https:// doi.org/10.1016/j.apenergy.2009.04.012

Cui, L. and Tang, X.Y. (2017). Optimized operation and sensitivity analysis of cogeneration microgrid. Electric Power Engineering Technology, 36, 138-143. (In Chinese)

Gamou, S., Yokoyama, R. and Ito, K. (2002). Optimal unit sizing of cogeneration systems in consideration of uncertain energy demands as continuous random variables. Energy Conversion and Management, 43(9-12), 1349-1361. https://doi.org/10.1016/S0196-8904(02) 00020-1

Gu, X.Y., Wang, S.P. and Gao, Z.S. (2010). Research progress on cold, heat and power triple production system. Thermal Power Generation, 39, 14-16. (In Chinese)

He, Y., Pan, B. and Yu, M.T. (2019). An operational reliability evaluation method based on important sampling-sequential Monte Carlo. Electric Power Science and Engineering, 35, 24-29. (In Chinese)

$\mathrm{Hu}, \mathrm{M}$. and Cho, H. (2014). A probability constrained multi-objective optimization model for CCHP system operation decision support. Applied Energy, 116, 230-242. https://doi.org/10.1016/j.apenergy. 2013.11.065

Kong, X.Q., Wang, R.Z. and Huang, X.H. (2005). Energy optimization model for a CCHP system with available gas turbines. Applied Ther- 
mal Engineering, 25(2-3), 377-391. https://doi.org/10.1016/j.appl thermaleng.2004.06.014

Li, M., Mu, H., Li, N. and Ma, B. (2016). Optimal design and operation strategy for integrated evaluation of CCHP (combined cooling heating and power) system. Energy, 99, 202-220. https://doi.org/10. 1016/j.energy.2016.01.060

Lin, A.B., Chen, H.W. and Fang, Y.L. (2007). Feasibility analysis of Stirling heat engine cogeneration system. Applied Energy Technology, 7, 1-4. (In Chinese)

Mago, P.J. and Chamra, L.M. (2009). Analysis and optimization of CCHP systems based on energy, economical, and environmental considerations. Energy and Buildings, 41(10), 1099-1106. https:// doi.org/10.1016/j.enbuild.2009.05.014

Park, Y.S., Park, S., Lee, J.S. and Choi, G.M. (2014). Effect of variation of fuel composition on gas turbine off-design performance. Applied Mechanics and Materials, 666, 194-198. https://doi.org/10. 4028/www.scientific.net/AMM.666.194

Ren, H., Zhou, W., Nakagami. K., Gao, W. and Wu, Q. (2010). Multiobjective optimization for the operation of distributed energy systems considering economic and environmental aspects. Applied Energy, 87(12), 3642-3651. https://doi.org/10.1016/j.apenergy.2010. 06.013

Ruan, Y., Liu, Q., Zhou, W., Firestone, R., Gao, W. and Watanabe, T. (2009). Optimal option of distributed generation technologies for various commercial buildings. Applied Energy, 86(9), 1641-1653. https://doi.org/10.1016/j.apenergy.2009.01.016

Tan, Z.F., Zhang, H.J., Shi, Q.S., Song, Y.H. and Ju, L.W. (2014). Multi-objective operation optimization and evaluation of largescale NG distributed energy system driven by gas-steam combined cycle in China. Energy and Buildings, 76, 572-587. https://doi.org/ 10.1016/j.enbuild.2014.03.029

Wang, L.F. and Singh, C. (2008). Stochastic combined heat and power dispatch based on multi-objective particle swarm optimization. International Journal of Electric Power and Energy Systems, 30, 226234. https://doi.org/10.1016/j.ijepes.2007.08.002

Wang, X., Xu, Y., Bao, Z., Li, W., Liu, F. and Jiang, Y. (2020). Operation optimization of a solar hybrid CCHP system for adaptation to climate change. Energy Conversion and Management, 220, 113010. https://doi.org/10.1016/j.enconman.2020.113010

Wei, B., Wang, Z.W. and Jiang, L. (2007). Economic analysis of microgas turbine cogeneration system. Thermal Power Generation, 9, 15. (In Chinese)

Xu, Y., Wang, Y., Li, S., Huang, G. and Dai, C. (2018). Stochastic optimization model for water allocation on a watershed scale considering wetland's ecological water requirement. Ecological Indicators, 92, 330-341. https://doi.org/10.1016/j.ecolind.2017.02.019

Yang, M.H., Ruan, Y.J. and Li, Z.Y. (2009). Simulation calculation of hourly cold and hot load in triple supply system. Refrigeration Air Conditioning \& Electric Power Machinery, 30, 85-88. (In Chinese)

Yong, M.C., Seo, D.H., Choi, D.W. and Roh, T.S. (2008). A study on defect diagnostics of gas-turbine engine on off-design condition using genetic algorithms. Journal of the Korean Society of Propulsion Engineers, 12(3), 60-67. (In Korean)

Zhou, Q.H. (2014). Optimization Analysis of Operation Mechanism of Natural Gas Cogeneration System. Master Dissertation, School of Electrical Engineering, Beijing Jiaotong University, Beijing, China.

Zhou, Z., Zhang, J., Liu, P., Li, Z., Georgiadis, M.C. and Pistikopoulos, E.N. (2013). A two-stage stochastic programming model for the optimal design of distributed energy systems. Applied Energy, 103, 135-144. https://doi.org/10.1016/j.apenergy.2012.09.019 